\title{
A visualization of the energy-saving problems
}

\author{
Svitlana Pryshchenko ${ }^{1 *}$, Yevgen Antonovych ${ }^{1}$, Andryi Petrushevskyi ${ }^{1}$ \\ ${ }^{1}$ Department of Information Technologies and Design, State University of Infrastructure and \\ Technologies, Kyrilivska str. 9, Kyiv 04071, Ukraine
}

\begin{abstract}
This paper focuses on the visualization of eco problems and the latest green technologies, including energy-saving. Today, there are four color-graphic means in advertising: photography, graphics (drawing or computer graphics), font compositions, and often a combination of these. Our study considers the imagery and stylistics of eco poster as a type of public advertising, and ascertains that in the subject of energy-saving a light bulb as the visual stereotype prevails. The paper indicates the importance of system design thinking, the use of creative approaches in the educational process of designers (metaphor, metonymy, hyperbole, association, allegory also) in creating social appeals for a wide audience - from young children to the older generation. Moreover, it emphasized the social value of design, and the aesthetic, moral as well as communicative aspects of visual information of environmental orientation within the context of this study.
\end{abstract}

\section{Introduction}

Today, special attention should be paid to advertising and information activities in the social sphere, in particular environmental, because of its important role in solving complex socio-cultural problems and educating society. The world community contributes to the active development of eco design and public advertising, greening Europe for social change and innovation at the global, glocal and local levels [1]. However, this support mainly concerns the financing of specific actions for the protection of the biosphere and the implementation of industrial development in everyday life in developed countries. The global task of today and the near future is to update effective energy-saving programs, which can 't be solved without shifting moral emphasis, guidelines, social priorities and practices in favor of harmonious human development and understanding of nature as the highest value. Critical content analysis of the aesthetic level of public advertising, especially in post-Soviet countries, revealed the use of outdated images, visual stamps and the lack of original ideas. Therefore, our research focuses on the relationship between graphic means and sustainability.

Design as a discipline has long been positioned from the context of developing and catering to the private good, focusing on individual and smaller sections of society - largely leaving its contributions to the common good underexplored. Within this context, the designers act as the important players in the formation and amelioration of any society [2].

Nowadays, the massive anthropogenic impact on the environment is apparent and clear. This puts an emphasis on the creation of the programs aiming at managing on the natural resources and conducting effective environmental protection. The authors consider this topic quite relevant. These are the development of social responsibility, eco consciousness,

\footnotetext{
${ }^{1 *}$ Corresponding author: akademiki@ukr.net
} 
creative self-expression and aesthetic education of pupils and students in the context of smart consumption strategy, popularization of eco-trends and eco design, promotion of clean cities, the formation of a new lifestyle in urban and rural environment, analysis of urban ecology, waste disposal, bioethics, studying the experience of European countries, improving the image of Ukraine in these matters.

And in a previous study, we noted that scientific articles in the "Nature" journal, publications of international organizations Greenpeace (USA) and World Wildlife Fund (Switzerland) are the most authoritative among foreign studies of environmental issues and the promotion of their solutions. In addition to publications and conferences, these organizations actively organize environmental seminars, exhibitions, fairs of eco products and eco design, as well as disseminate information about the environment through the Media. Although we still see an insufficient number of environmental social challenges in the media space - outdoor advertisements and single articles on news portals are the most common [3].

Noting the insufficient number of environmental social appeals in the modern media space (sometimes in Ukraine we can find outdoor advertising and some articles on news portals), we present an impressive fact - according to the monitoring of the Institute of Mass Media in 2016, only $1 \%$ of materials in Ukrainian online media, covering mainly foreign experience [4]. Over the next 5 years, the situation has not changed.

\section{Materials and methods}

Socio-humanitarian knowledge of the $20^{\text {th }}$ and $21^{\text {st }}$ centuries characterized by the emergence of new interdisciplinary areas, among which should be singled out "visual researches". The system-structural method chosen for this study allows the analysis of Design as a complex field of activity at the junction of science, art and technology: both at the level of analysis of individual factors and at the level of their synthesis in the disclosure and understanding of functional, technological, marketing and cultural aspects of visual information. environment: urban, subject, virtual, etc. In Design, a system is understood as a set of necessary and sufficient elements that are in an established relationship and form a single whole. The set of components covers socio-economic issues, problems of synthesis of utilitarian and aesthetic aspects, environmental friendliness, rational use of materials. Each structural element of the form in the design performs certain functions that meet the needs of the system as a whole. Thus, Design can be understood as a creative method, process and result of art and design activities to meet the utilitarian, social and aesthetic needs of the consumer, and the poster in this case is a tool that can be used productively to harmonize human life.

The article "Green gold" highlights that the round-up on last year's global investment in clean energy shows that renewables continued their rapid ascendancy, bringing multiple benefits for all [5]. In recent years, many authors analyze not only the problems of energysaving as such, but also related educational and behavioral aspects, as well as development strategies in Future [6-16].

Sociologist Robin Cohen believes that posters, placards, advertising appeals are examples of creolization, as they combine the verbal part with the visual, which belongs to a different sign system than language. According to him, creolization occurs when designers choose certain elements of cultures, give them new meanings and creatively combine to create new images that become products of mass culture [17].

Advertising is a manifestation of semantic concepts, and the global trend is the direction of advertising graphics in the direction of transferring the functions of influence from its verbal part to the visual. The visual series no longer performs an illustrative-decorative function, but is formed as a visual-verbal model, the language of which is based on the 
techniques and means of fine arts. The use of visual means in advertising should be due to the focus on the target audience, taking into account actual topics.

The meaning of the information should be perceived by the person "in motion", and this will determine the visual shape of the poster - size, conciseness of the image, easy-to-read font, bright colors. In advertising posters often uses photography, symbolic elements, associative and emotional methods of influencing potential consumers. Eco poster belongs to non-commercial mass media. The ability to see and reflect an idea in a poster, and poster thinking - the main feature of a poster artist. The poster made at a high artistic level can be an important factor in positive aesthetic action. For more than a hundred years, "green" advertising has been educating environmentally conscious people, becoming brighter and more expressive.

The history of eco poster began in 1906, when the American Public Association organized the protection of Niagara Falls from the damage caused to it by energy companies. New trends in Art (constructivism, futurism, cubism, symbolism) stimulated the further development of the poster. Since 1961, the World Wildlife Fund has been actively covering environmental issues, and nowadays (Fig. 1).

The famous Swiss graphic designer Mueller-Brockmann believed that the poster is the most effective means of visual communication, it should stimulate, explain, provoke, persuade. Its form should be easy and accessible, however, to achieve this is much more difficult than to express oneself the artist in the painting [18].

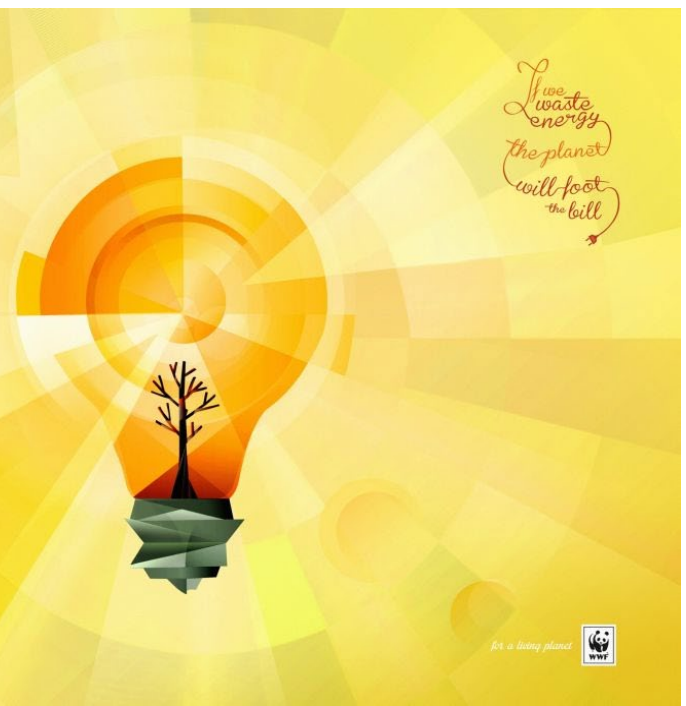

Fig. 1. WWF, the World Wildlife Fund energy-saving poster, 2016 [19]

It should be noted that in the Soviet Union in the second half of the $20^{\text {th }}$ century, a large number of propaganda posters in various graphic techniques were created on the use of atomic energy for peaceful purposes, directed against the nuclear arms race. The technique of work execution - watercolors, gouache, colored pencils. Such posters at exhibitions, in schools and industrial premises raised patriotic feelings through acquaintance with historical events in the life of the country (Fig. 2), and the whole World. The main role in raising the poster was played by competitions and exhibitions held by the Union of Artists and publishing houses in Moscow, Kyiv and Kharkiv. 

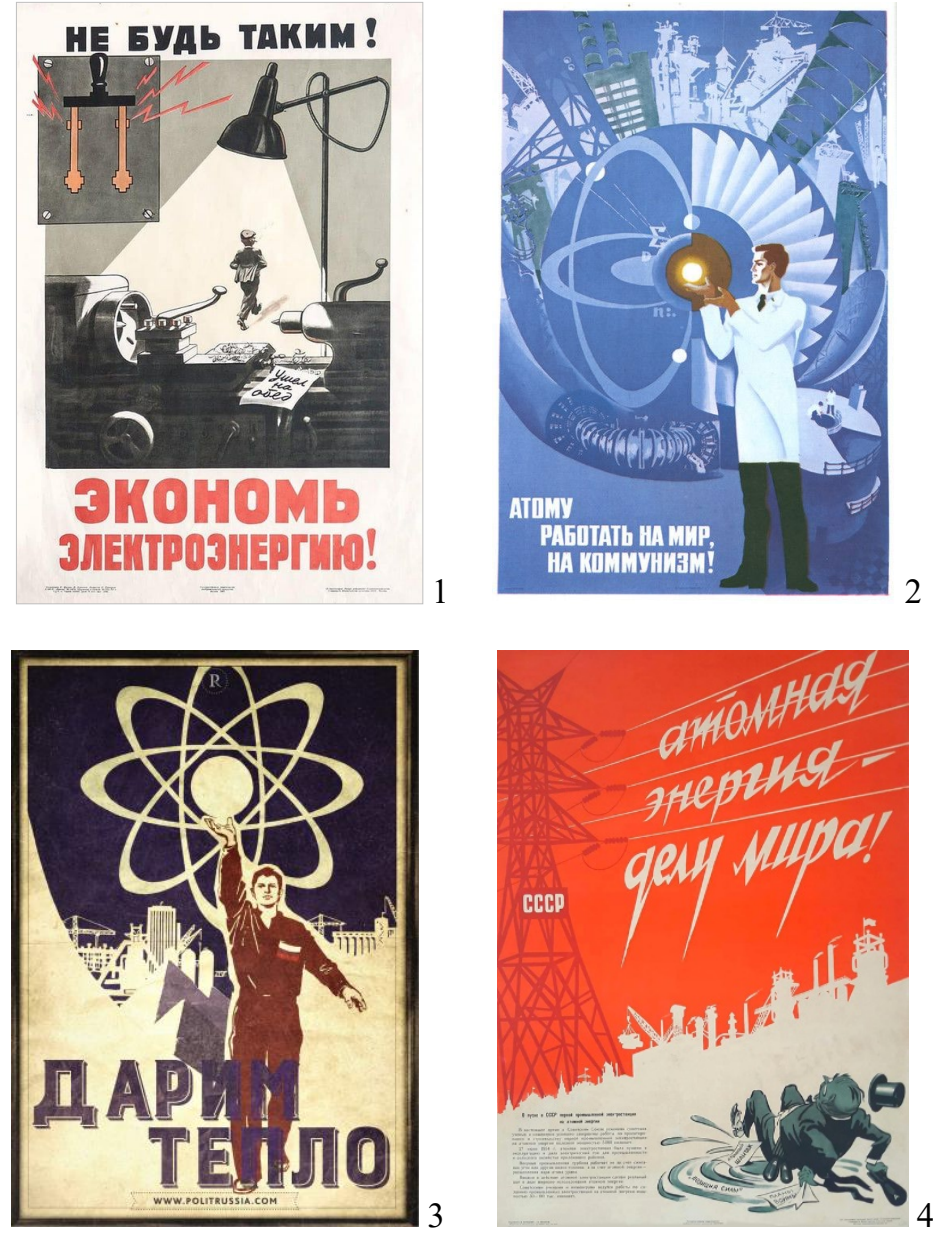

Fig. 2. Soviet posters, 1980s: 1. Don't Be Like That! Save Electricity! 2.Atom to work for Peace, for Communism! 3. We give warmth 4.Nuclear energy for the cause of Peace!
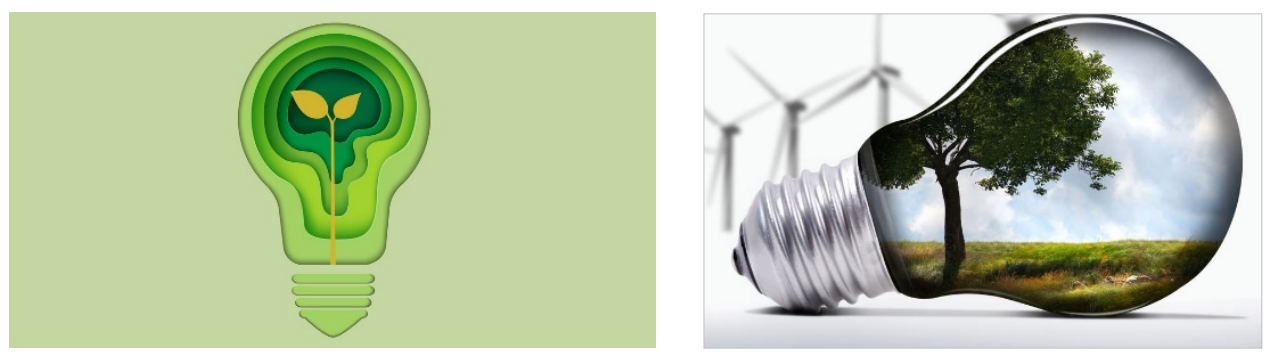

Fig. 3. Visual stereotypes for energy-saving

In Ukraine, the Kharkiv State Academy of Design and Arts became the founder of the International Triennial of eco posters " $4^{\text {th }}$ Block". The triennial owes its name to Unit 4 of the Chernobyl. The " $4^{\text {th }}$ Block" exhibition was first held in 1991 as a tribute to the heroes who took part in the aftermath of the Chernobyl explosion. The exhibition has become an important event in the tandem of graphic design and ecology. The triennial collection includes several thousand works. The main purpose of this exhibitions is to draw the attention 
of the world community to environmental problems, the consequences of social, man-made and natural disasters (Fig. 4). The Ukrainian Association of Graphic Designers aims to unite efforts to help solve environmental problems through poster art, education of environmental awareness. Due to this, the association has achieved wide international recognition. The " 4 th Block" is not an elite creative forum closed to self-sufficient formal searches. It has a special social orientation, close and understandable to everyone and attracts more and more participants from different countries and continents.
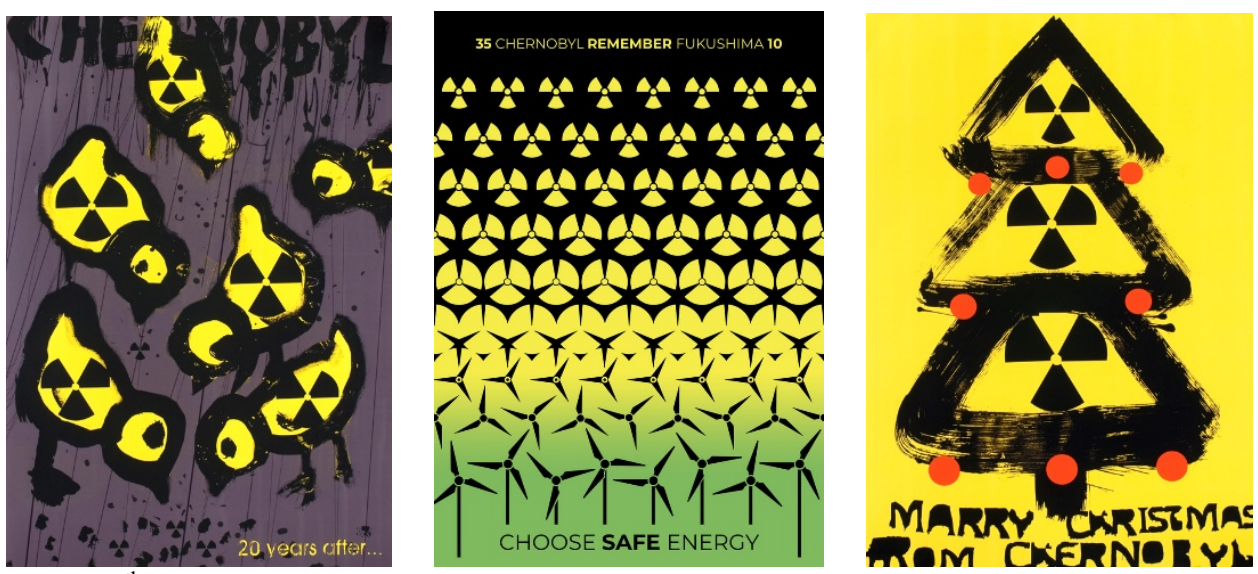

Fig. 4. $4^{\text {th }}$ Block posters, 2006-2021

\section{Results and discussions}

Designers, who working in the media, based on the perception of color drawings and photographs, must develop strategies for visualizing the invisible - advertising ideas: this is a fundamental paradox of advertising. Compared to verbal language, visual elements are perceived faster, easier, more accurately. The poster must conform to the important principle of semantic integrity, which consists of physical, psychological and symbolic totality and strong internal connections. All color elements: illustrations, headings, text blocks, corporate constants, are combined into a common image, interact closely and determine its effectiveness, not only commercial but also social. Given the largest coverage of the population, the most effective means for eco poster is outdoor: billboards, city lights, advertising on transport and in the subway [20].

In the comparative study, the authors identified significant shortcomings of modern advertising graphics: the predominance of stereotypes, primitiveness, vulgarity and pop art, kitsch, eclecticism, as become cultural dominants. There is no visual culture of color, its conciseness and restraint. We distinguish three main visual means - photography, graphics (drawing or computer graphics), font compositions, and 4th, the most common tool - a combination of them: photos, drawings, or ornaments with background geometric screensavers. As a rule, modern posters are a combination of different visual means in one way or another. But the contemporary poster needs interesting images, non-standard, emotion, humor or satire, so the use of creative technologies in creating an advertising appeals - metaphors, metonymy, allegory, association, hyperbole - is becoming increasingly important. Among the common stylistic trends are minimalism, constructive style, postmodernism (eclecticism in a combination of various visual means: drawn characters, graphic elements, text blocks, photographs, works of art).

The use of visual metaphors in the poster indicates that they have significant potential and persuasiveness, perhaps on a subconscious level, and, as a result, have a result. Metaphor 
as a creative technique and means of communication becomes a basic characteristic of modern visual culture, a tool for integrating abstract and concrete, interpretation of complex aspects of worldview, ideas and combining images with emotions, a means of creating and emphasizing new meanings, which is so important in advertising.

Hyperbole is the second most frequently used technology in advertising. Exaggerating the positive characteristics of a product or service enhances the expressiveness and emphasizes the originality of the message.

When creating public advertising, designers should choose a few basic associations, rather than trying to gather all the feelings and associations. It is clear that this is difficult and requires appropriate visualization. By developing one (or more) stable positive associations, the customer and the designer get the opportunity to increase the social value of the selected object.

Allegory - dissent, creative advertising technology that avoids banality, cliches, presenting objects.

Metonymy ranks last among advertising technologies in terms of frequency of use, as it is not as simple a technique as it seems at first glance. The transition from form to form, renaming is more complicated than metaphor - the foreign language of metonymy is based on the definition of one object through another in close connection, comparison, irrational in its nature.

British designer Tolly defines "new simplicity" with visual trends of the present and the near future: clear structure of advertising information, conciseness, minimalism in the use of graphics, pronounced contrast, and limited colors. Tolly claims that decorative design, posters, branding, packaging, printing, and WEB design have saturated the market over the last decade. Minimalism is not so much a trend as a "barometer of social change". In the 1950 s, graphic minimalism was a way to overcome the dominance of advertising. Modern minimalism is a form of restraint that comes to the fore as a reaction to clearly expressive graphics, as a response to the visual excess of the 1990 s - early 2000s. There used to be a lot of interest in the culture of postmodernism, and everyone who showed itself reflected it in the poster. It was very decorative and very "loud". According to him, we are now in a period of austerity, and this ideologically visualizes minimalism [21].

The current environmental situation gave rise to the organizing a joint German-Ukrainian project "ECO-culture" on the base of Munich Ludwig Maximilian University (LMU) for holding a contest of environmental drawings for children and youth in the framework of the Munich-Kyiv partnership (September - December 2015; the concept and presiding over by Pryshchenko). The aim of the project was a development of eco thinking, eco education and long-term collaboration of the civic communities of Germany and Ukraine, popularization of eco trends, forming a new lifestyle with the means of poster art, and promoting the concept of clean cities, consumer culture and energy-saving. It was the first step. In eco poster competition was attended by more than 70 children from different countries living in Munich: Ukraine, Italy, Germany, Poland, Bulgaria, Greece, Latvia, Hungary, France, Serbia, India, Kosovo, Croatia, Romania, and Iraq. In 2016, she conducted a thematic workshop "Environmental public advertising as a visual-verbal model in the structure of modern media" for LMU students.

The next stage was organizing the exhibition based on the results of eco poster competition among students of the National Academy of Culture and Art Management, whose posters were presented in May 2017 at the "Pecherskaya" gallery (Kyiv). A total of 90 posters were presented in the exhibition. All contestants were awarded an ecological kit (eco notebook, eco pen and eco package) from recycled packaging from the company "Tetra Pak", and the winners - diplomas, design books, and art materials.

Thus, as a further development of the project, in early 2021 the State University of Infrastructure and Technologies (Kyiv) began the International virtual eco poster competition 
among students from European countries: Poland, Germany, Ukraine, Czech Republic, Lithuania, Latvia, Belarus, Moldova, Georgia, Croatia, Greece, Azerbaijan, Armenia also. The main goal of the competition is to draw public attention to modern environmental threats, to identify the creative potential of young people in caring for natural resources, understanding significant biodiversity loss, climate change, biosphere protection, energy control, and possible ways to solving these eco problems.

International socio-cultural designing in this direction is quite interesting and promising, the main focus of which will be ecology and in-depth study of regional cultures and their manifestations in the modern media space, holding exhibitions of eco posters within the integrated Carpathian summer and winter schools in Ukraine.

\section{Conclusions}

Overall, we can conclude that energy-saving problems can often be neglected in today's globalized and sophisticated world if compared with waste management or global warming and climate change issues. The system-structural analysis of the poster's visual means revealed tendencies of straightforwardness and stereotypes, if these images are created without design education and a deep understanding of the subject.

Prospects for the use of research results are as follows. The obtained scientific results will be important at the theoretical, practical and educational levels and will generally contribute to the development of eco poster. Some of the statements are debatable and require further research in the field of visual culture, digital media in order to implement modern design concepts of energy-saving. Design and advertising face the growing imbalance of resources and consumption in the future, and must be based on new socio-cultural principles of harmonious coexistence of the individual, society, state, economy, culture, etc.

\section{References}

1. European Green Week, https://www.eugreenweek.eu (2020)

2. Swissdesignnetwork, https://swissdesignnetwork.ch/symposia/design-as-common-good (2020)

3. O. Novikova, S. Pryshchenko, Herald of the National Academy of Culture and Art Management, 3, 57-61 (2016)

4. Detector Media, www.detector.media/monitoring/article/119349/2016-10-04-ukrainskiinternet-zmi-zgaduyut-pro-ekologichnu-temu-lishe-v-1-svoikh-materialiv-imi (2016)

5. Green gold. Nature energy, 2016. 1, 16011; https://doi.org/10.1038/nenergy.2016.11

6. U. Ablayeva, N. Normatova Problems of Architecture and Construction, 2, 1, 7 (2019)

7. R. Bull, J. Romanowicz, N. Jennings, M. Laskari, G. Stuart, D. Everitt, International Journal of Sustainability in Higher Education, 19(7), 1220-1238 (2018)

8. P. Fraternali, F. Cellina, S.L.H. Gonzales, M. Melenhorst, J. Novak, C. Pasini, C. Rottondi, A. Emilio Rizzoli. Visualizing and gamifying consumption data for resource saving: challenges, lessons learnt and a research agenda for the future. Energy Informatics, 2, 22 (2019)

9. T.G. Holmes, Proceedings of the $6^{\text {th }}$ ACM SIGCHI Conference on Creativity \& Cognition, 153-162 (2007)

10. M. Iordache Platis, J. Romanowicz, Sustainability, 12(22), 9626 (2020)

11. K. Koroleva, M. Melenhorst, J. Novak, S.L.H. Gonzales, P. Fraternali, A. Rizzoli, Energy Informatics, 2(1), 1-20 (2019)

12. Y. Liu, J. Liang, X. Wang, Y. Ouyang, Sustainable Development, 3, 116-122 (2013) 
13. S. Pahl, J. Goodhew, C. Boomsma, S.R. Sheppard, Frontiers in Psychology, 7, 92 (2016)

14. I. Čábelková, W. Strielkowski, I. Firsova, M. Korovushkina, Energies, 13(7), 1742 (2020)

15. Y. Tange, S. Kiryu, T. Matsui, Y. Fukuyama, IEEJ Transactions on Electronics, Information and Systems, 134(1), 78-84 (2014)

16. E. Van der Werff, D. Taufik, L. Venhoeven, Energy Research \& Social Science, 54, 2633 (2019)

17. R. Cohen, Globalizations, 4 (3), 369-384 (2007)

18. J. Müller-Brockmann, History of the Poster (2004)

19. WWF, https://wwf.panda.org/wwf_offices/switzerland (2016)

20. S. Pryshchenko, Design and Advertising (2020)

21. S. Tolley, The new simplicity in Graphic Design (2016) 